
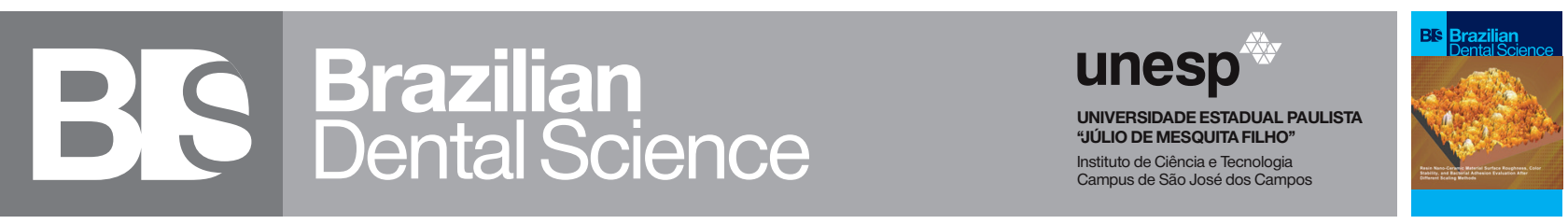

\title{
In Vitro Evaluation of a Recently Developed Rotary File: AF Rotary
}

\author{
Avaliação in vitro de um arquivo rotativo desenvolvido recentemente: AF Rotary
}

Marco SERACCHIANI ${ }^{1}$, Orlando DONFRANCESCO ${ }^{1,2}$, Michela RELUCENTI ${ }^{2}$, Rodolfo REDA ${ }^{1}$, Alessio ZANZA ${ }^{1}$, Gianluca GAMBARINI ${ }^{1}$, Luca TESTARELLI ${ }^{1}$

1 - Sapienza University of Rome, Department of Oral and Maxillo Facial Sciences, Rome, Italy.

2 - Sapienza University of Rome, Department of Anatomy, Histology, Forensic Medicine and Orthopedics, Rome, Italy.

\begin{abstract}
Objective: Aim of the present study is to evaluate mechanical properties of a newly developed rotary file, AF Rotary (Fanta Dental, Shanghai, China), and to compare these features with a worldwide spread rotary file, Protaper Gold F2 (PTG F2; Dentsply Maillefer, Ballaigues, Switzerland). Material and Methods: 60 AF Rotary 25.06 and 60 PTG F2 were divided in three groups of 20 files each. A group underwent to cyclic fatigue resistance tests, second group underwent to torsional resistance tests, third group underwent to bending tests. The statistical analysis was performed using $t$ student test with significance level set at 95\% ( $\mathrm{p}<0.05)$. Results: AF Rotary showed significantly higher torsional resistance and cyclic fatigue resistance $(\mathrm{p}<0.05)$ when compared to the PTG F2. AF Rotary also showed significantly lower bending resistance $(\mathrm{p}<$ 0.05) when compared to the PTG F2. Conclusion: Therefore, within the limitations of this study, the results show better performances for AF Rotary compared to PTG F2 regarding the cyclic fatigue test, the torsional test and the bending test. Since the PTG F2 is a commonly used and widely investigated instrument it could be possible to state that the AF Rotary exhibits remarkable in vitro performances.
\end{abstract}

\section{KEYWORDS}

AF Rotary; Protaper gold; NiTi rotary instruments; Cyclic fatigue; Torsional resistance.

\section{RESUMO}

Objetivo: O objetivo do presente estudo é avaliar as propriedades mecânicas de uma lima rotativa recémdesenvolvida, AF Rotary (Fanta Dental, Shanghai, China), e comparar essas características com uma lima rotativa mundialmente difundida, Protaper Gold F2 (PTG F2; Dentsply Maillefer, Ballaigues, Suíça). Material e Métodos: 60 AF Rotary 25.06 e 60 PTG F2 foram divididos em três grupos de 20 arquivos cada. Um grupo foi submetido a testes de resistência à fadiga cíclica, o segundo grupo foi submetido a testes de resistência à torção, o terceiro grupo foi submetido a testes de flexão. A análise estatística foi realizada por meio do teste $\mathrm{t}$ student com nível de significância de 95\% ( $\mathrm{p}<0,05)$. Resultados: AF Rotary apresentou resistência torcional e resistência à fadiga cíclica significativamente maiores $(p<0,05)$ quando comparado ao PTG F2. AF Rotary também apresentou resistência à flexão significativamente menor $(\mathrm{p}<0,05)$ quando comparado ao PTG F2. Conclusão: Portanto, dentro das limitações deste estudo, os resultados mostram melhores desempenhos do AF Rotary em relação ao PTG F2 no que diz respeito ao teste de fadiga cíclica, ao teste de torção e ao teste de flexão. Uma vez que o PTG F2 é um instrumento comumente usado e amplamente investigado, pode-se afirmar que o $\mathrm{AF}$ Rotary exibe desempenhos in vitro notáveis.

\section{PALAVRAS-CHAVE}

Rotativo AF; Protaper ouro; Instrumentos rotativos NiTi; Fadiga cíclica; Resistência à torção. 


\section{INTRODUCTION}

$\mathrm{T}$ he introduction of nickel-titanium (NiTi) alloy for endodontic instruments in the last decades has significantly improved the simplicity, the predictability and duration of the root canal treatment (RCT), by reducing number of instruments to achieve an adequate level of shaping. Despite many advantages, these instruments are subjected to repeated and high stress, related to the complexity of root canal anatomy, and intracanal separation of rotary NiTi instruments is still a rather frequent iatrogenic error that may negatively affect the outcome of the treatment [1-5]. Since intracanal separation are often difficult to predict, is very important to minimize the risk of intracanal separation with an accurate threedimensional study of roots anatomy, and to correctly visualize canal trajectories, using cone beam computed tomography (CBCT), avoiding superimposition of hard tissues $[6,7]$. It is also possible to identify diverging or confluent canals, hidden curvatures and bifurcation, that represent the most stressful conditions for NiTi instruments. Unfortunately, CBCT on a routine basis is nowadays used only by a minority of clinicians due to increased costs and radiation risk.

It's evident that is not possible to modify the root canal anatomy, therefore it's important to use safer motions during instrumentation and to improve mechanical performances of the new NiTi instruments. The most common studies available in the literature are in vitro evaluations and comparisons of mechanical properties of the NiTi instruments. These studies investigated mainly the following properties: flexibility, cutting efficiency, cyclic fatigue and torsional resistance.

Cyclic fatigue is the ability to resist to repeated cycles of tension and compression in a curved canal and it is an evaluation factor of flexural strength during bending. Torsional resistance is the instrument's ability to be not damaged when the tip becomes wedged in the canal and the shaft continues to rotate. In addition, also flexibility is an important property related with the behavior of NiTi files during the root canal preparation. Two were found to be most relevant factors influencing the above mentioned properties: the heat treatment and the mass of the NiTi instruments [8-14]. The heat treatment modifies the metallurgical properties of the instrument, and change its behavior simply changing the transition temperature of the alloy from a more austenitic to a more martensitic one [15-20]. A more martensitic file will be more resistant to flexural stress, while a more austenitic instrument will be more resistant to torsional fatigue [21-27]. In addition to the heat treatment, the mass at the point of maximum stress also has great importance for the resistance of the instrument. Higher the mass, higher the torsional resistance will be, but on the contrary, it will be less resistant to flexural failure [13]. From this evidence it's possible to say that improving a specific property of an instrument may result in decreasing other properties.

For each new instrument produced, it would be important to ideally test in vitro all these characteristics, or at least many of them, although it's difficult to integrate how these characteristics interact with each other and what the clinical behavior of the instrument will be. Therefore, the aim of the present study was to compare the different properties (cyclic fatigue resistance, torsional resistance, and bending properties) of two different NiTi rotary files, $\mathrm{AF}^{\mathrm{TM}}$ Rotary, an instrument recently introduced in the market, and F2 PTG, a well-studied and worldwide spread rotary file.

\section{MATERIAL AND METHODS}

Sixty $\mathrm{AF}^{\mathrm{TM}}$ Rotary (Fanta Dental, Shanghai, China) and 60 PTG F2 (Dentsply Maillefer, Ballaigues, Switzerland) have randomly divided into 3 groups of 20 instruments each. Three 
groups have been randomly selected to be tested for three different characteristics: cyclic fatigue resistance, torsional resistance, and flexibility. Before undergoing these three tests, all the 120 rotary files were previously examined through stereomicroscope (Carl Zeiss Micro Imaging, Göttingen, Germany) at $20 \times$ magnification to detect any macroscopic defects. No rotary files were rejected due to shape defects. The same operator performed all the tests, to avoid differences due to operator skills.

\section{Cyclic Fatigue Test}

$20 \mathrm{AF}^{\mathrm{TM}}$ Rotary and $20 \mathrm{~F} 2$ PTG were tested using a device already validated in the previous study to evaluate cyclic fatigue, made of two main parts: a stainless steel artificial (SS) canal with a $90^{\circ}$ angle and $5 \mathrm{~mm}$ of curvature and a hand piece connected to a mobile device which allowed easy repeatable insertion of the instrument in the abovementioned SS root canal. The NiTi rotary files were inserted for $16 \mathrm{~mm}$ inside the canal and rotated with the speed and the torque recommended by the manufacturer, $500 \mathrm{rpm}$ and $2.6 \mathrm{Ncm}$ for AF Rotary and $300 \mathrm{rpm}$ $2.5 \mathrm{Ncm}$ for PTG F2. The time to fracture was recorded using a chronometer (1/100 seconds), and the time was stopped as soon as breaking sounds were heard or visible signs of fracture were detected. Finally, the number of cycles to fracture (NCF) was calculated by multiplying the time to fracture for the rotational speed. The lengths of the collected fragments were measured using a digital caliper.

\section{Torsional Resistance Test}

A torsional test was performed on the instrument by blocking the apical $3 \mathrm{~mm}$ of each of the files to calculate $\mathrm{TtF}$ using a new device validated in recently published studies $[28,29]$. This device consists of two main parts, a hand piece connected on one side to an electric motor (KaVo, Biberach, Germany) allowing a real-time (0.1 seconds) recording of the torque with a sensitivity of $0.05 \mathrm{Ncm}$ and a vise used to firmly secure the apical $3 \mathrm{~mm}$ of the NiTi instruments. The two above mentioned machines were linked using a mobile device to allow repeatable placement of the files inside the vise. All the instruments were rotated at the same speed, 300 $\mathrm{rpm}$. The torque value set on the motor was 5.5 $\mathrm{Ncm}$, to ensure a precise recording in a range from 0.05 to $5.5 \mathrm{Ncm}$. The $\mathrm{TtF}$ was registered for each instrument by the integrated software of the hand piece and calculated using a spreadsheet.

\section{Bending Test}

The bending test was performed by the using of a custom-made device with a load cell and guarantees a correct and reliable recording value expressed in grams ( $\mathrm{g}$ ). The tip of the instrument was locked for $3 \mathrm{~mm}$ with a vise to the calibrated load cell. Once the instrument underwent an elastic displacement and reached an excursion of $45^{\circ}$, the moment of bending was recorded. This test was carried out for all the tested instruments.

\section{Statistical Analysis}

The data from all tests were collected, then mean and standard deviation were calculated for NCF, FL, TtF and bending resistance. The statistical analysis was performed using t student test with significance level set at 95\% ( $<<0.05)$.

\section{RESULTS}

Table I shows the results of cyclic fatigue tests, reporting mean values and standard deviation of NCF and fragment lengths (FLs). AF Rotary showed statistically significant higher values of NCF than PTG F2 ( $p<0.05)$.

Table I - Mean and $p$ values for Number of Cycles to Failure (NCF) and Fragment length (FL) of AF Rotary and PTG F2

\begin{tabular}{|ccccc|} 
& \multicolumn{2}{c}{ NCF } & \multicolumn{2}{c|}{ Bending } \\
& AFRotary & PTGF2 & AF Rotary & PTGF2 \\
\hline Mean \pm SD & $605.5 \pm 22.7$ & $300.5 \pm 19.92$ & $6.04 \pm 0.28$ & $6.075 \pm 0.01$ \\
\hline p value & 0.002 & \multicolumn{2}{c}{0.85}
\end{tabular}


Table II shows the results of the torsional resistance and bending test; the AF Rotary showed significantly higher torsional resistance ( $\mathrm{p}<0.05$ ) when compared to the PTG F2. AF Rotary also showed significantly lower bending resistance ( $\mathrm{p}<0.05$ ) when compared to the PTG F2.

Table II - Mean and $p$ values for Torque to Fracture (TtF) and bending test of AF Rotary and PTG F2

\begin{tabular}{|ccccc|} 
& \multicolumn{2}{c}{ TtF } & \multicolumn{2}{c}{ Bending } \\
& AF Rotary & PTGF2 & AFRotary & PTGF2 \\
\hline Mean \pm SD & $1.42 \pm 0.01$ & $1.39 \pm 0.01$ & $24 \pm 1.15$ & $50 \pm 2.30$ \\
p value & \multicolumn{2}{c}{0.002} & \multicolumn{2}{c}{0.000}
\end{tabular}

\section{DISCUSSION}

Whenever a new NTR file is released on the market, the main concern is about the lack of scientific literature that proves the in vitro properties of the new file and compare it with instruments already present on the market and with a validated scientific background. Therefore, the most common tests, such as cyclic fatigue test, bending test and torsional resistance test, are needed to provide information about the instrument resistance and performance. Thus, in order to validate the reliability of the $\mathrm{AF}^{\mathrm{TM}}$ Rotary 25.06 , in the present study this instrument was submitted to the above mentioned tests and the results have been compared to a deeply studied and worldwide used rotary instrument: the Protaper Gold F2. This comparison is justified not only by the proven efficacy of the PTG F2 but also by the fact that the two instruments share the same cross-section design. Moreover, both files are thought to be the last instrument of their sequence, prior to apical refining.

The PTG F2 is a rotary instrument that presents a tip diameter of $0.25 \mathrm{~mm}$, a 0.08 variable taper and a convex triangular cross sectional design. It presents a heat-treated alloy deeply analyzed and validated in literature: the Gold Wire (Dentsply Maillefer, Ballaigues, Switzerland).
This heat-treatment, according to previous published studies, enhances the cyclic fatigue resistance and flexibility of the instrument in order to better withstand anatomical complexities and curvatures $[8,11,12,18,21,27,28]$.

The $\mathrm{AF}^{\mathrm{TM}}$ Rotary is a NiTi rotary instrument that presents a convex triangular cross section with three blades along the cutting surface. It presents a $0.25 \mathrm{~mm}$ tip diameter as well and a 0.06 constant taper. An innovative characteristic of the instrument is the proprietary heat treatment, the AF-H wire (Fanta Dental, Shanghai, China). This heat treatment should increase both torsional and flexural resistance according to manufacturer internal studies, but there are no published studies regarding this heat treatment.

Moreover, to date there are no studies comparing the two proprietary heat treatments, the results showed higher cyclic fatigue resistance, higher torsional resistance and an increased flexibility of the AF Rotary compared to the PTG F2.

The two instruments present different amount of mass, since the PTG F2 has a 0.08 variable taper while the $\mathrm{AF}^{\mathrm{TM}}$ Rotary has a 0.06 constant taper. This mass difference should lead to the conclusion, supported by the published literature, that bigger the dimensions of the instrument, higher the torsional resistance would be $[13,14,29]$. Despite that, the results of the torsional resistance test highlight higher values for the $\mathrm{AF}^{\mathrm{TM}}$ Rotary. These unexpected results can be only explained by the new manufactured heat-treated alloy, the AF-H wire, which was able to increase, according to manufacturer internal studies, the metallurgical properties, providing also an improved resistance to torsional stresses.

The flexibility of these NiTi rotary instruments does not depend on the cross sectional design but it depends mainly on the properties of their alloy. The two instruments present indeed a different heat-treatment, which changes the phase of the alloy. From the result 
of the study it is clear that the $\mathrm{AF}^{\mathrm{TM}}$ Rotary has a more flexible behavior if compared to the PTG F2. This result could be explained by the fact that, according to manufacturer internal studies, the $\mathrm{AF}^{\mathrm{TM}}$ Rotary alloy exhibits at room temperature a martensitic phase, that contributed to enhance flexibility $[5,8,16]$. Furthermore, it is logical to expect that the AF-H wire would enhance fatigue lifespan of the instrument as well, as confirmed in the results of the cyclic fatigue test. Moreover, the above mentioned results can also be explained by the lower mass of the AF Rotary, the less the mass the more flexible the instrument is $[13,14,26]$.

\section{CONCLUSIONS}

Therefore, within the limitations of this study, the results show better performances for AF Rotary compared to PTG F2 regarding the cyclic fatigue test, the torsional test and the bending test. Since the PTG F2 is a commonly used and widely investigated instrument it could be possible to state that the AF Rotary exhibits remarkable in vitro performances. Obviously, the present study has the limitations of reporting in vitro results, which may not be confirmed by in vivo performances. In conclusion, these results could be considered as a promising and exhaustive preliminary evaluation of the instrument, but further in vivo evaluation should be done in order to complete the general overview of the instrument.

\section{Funding}

This research received no external funding.

\section{Conflict of interest}

The authors have no proprietary, financial, or other personal interest of any nature or kind in any product, service, and/or company that is presented in this article.

\section{Regulatory Statement}

Not applicable.

\section{REFERENCES}

1. Coelho MS, Rios MA, Bueno C. Separation of nickel-titanium rotary and reciprocating instruments: a mini-review of clinical studies. Open Dent $J$. 2018;12:864-72.

2. Gambarini G, Miccoli G, Seracchiani M, Morese A, Piasecki L, Gaimari G, et al. Fatigue resistance of new and used nickel-titanium rotary instruments: a comparative study. Clin Ter.2018;169(3):e96-e101.

3. Gambarini G, Galli M, Seracchiani M, Di Nardo D, Versiani MA, Piasecki L, et al. In vivo evaluation of operative torque generated by two nickel-titanium rotary instruments during root canal preparation. Eur J Dent. 2019;13(4):55662.

4. Gambarini G, Seracchiani M, Piasecki L, Valenti Obino F, Galli M, Di Nardo D, et al. Measurement of torque generated during intracanal instrumentation in vivo. Int Endod J. 2019;52(5):737-45.

5. Miccoli G, Gaimari G, Seracchiani M, Morese A, Khrenova T, Di Nardo D. In vitro resistance to fracture of two nickel-titanium rotary instruments made with different thermal treatments. Ann Stomatol (Roma). 2017;8(2):53-8.

6. Segato AVK, Piasecki L, Felipe Iparraguirre Nuñovero M, da Silva Neto UX, Westphalen VPD, Gambarini G, et al. The accuracy of a new cone-beam computed tomographic software in the preoperative working length determination ex vivo. J Endod. 2018 Jun;44(6):1024-9. doi:101016/j. joen.2018.02.027.

7. Valenti-Obino F, Di Nardo D, Quero L, Miccoli G, Gambarini G, Testarelli L, et al. Symmetry of root and root canal morphology of mandibular incisors: a cone-beam computed tomography study in vivo. J Clin Exp Dent. 2019;11(6):e527-e33.

8. Alcalde MP,Duarte MAH, Bramante CM, de Vasconselos BC, Tanomaru-Filho $M$, Guerreiro-Tanomaru JM, et al. Cyclic fatigue and torsional strength of three different thermally treated reciprocating nickel-titanium instruments. Clin Oral Investig. 2018;22(4):1865-71.

9. Miyai K, Ebihara A, Hayashi Y, Doi H, Suda H, Yoneyama T. Influence of phase transformation on the torsional and bending properties of nickel-titanium rotary endodontic instruments. Int Endod J. 2006;39(2):119-26.

10. Di Nardo D, Galli M, Morese A, Seracchiani M, Ferri V, Miccoli G, etal. A comparative study of mechanical resistance of two reciprocating files. J Clin Exp Dent. 2019;11(3):e231-e5.

11. Gambarini G, Galli M, Di Nardo D, Seracchiani M, Donfrancesco 0, Testarelli L. Differences in cyclic fatigue lifespan between two different heat treated NiTi endodontic rotary instruments: WaveOne Gold vs EdgeOne Fire.J Clin Exp Dent. 2019;11(7):e609-e13.

12. Ounsi HF, Nassif W, Grandini S, Salameh Z, Neelakantan P, Anil S Evolution of nickel-titanium alloys in endodontics. J Contemp Dent Pract 2017;18(11):1090-6.

13. Gambarini G, Miccoli G, Seracchiani M, Khrenova T, Donfrancesco 0, D'Angelo $\mathrm{M}$, et al. Role of the flat-designed surface in improving the cyclic fatigue resistance of endodontic niti rotary instruments. Materials (Basel). 2019 Aug 8;12(16):2523. doi:10.3390/ma12162523.

14. Kaval ME, Capar ID, Ertas H, Sen BH. Comparative evaluation of cyclic fatigue resistance of four different nickel-titanium rotary files with different crosssectional designs and alloy properties. Clin Oral Investig. 2017;21(5):1527-30.

15. Silva E, Giraldes JFN, de Lima CO, Vieira VTL, Elias CN, Antunes HS. Influence of heat treatment on torsional resistance and surface roughness of nickeltitanium instruments. Int Endod J. 2019;52(11):1645-51.

16. Yahata Y, Yoneyama T, Hayashi Y, Ebihara A, Doi H, Hanawa T, et al. Effect of heat treatment on transformation temperatures and bending properties of 
nickel-titanium endodontic instruments. Int Endod J. 2009;42(7):621-6.

17. Yang YJ, Hou BX, Hou XM. [Metallurgic behavior and mechanical property of nickel-titanium endodontic files made by 3 heat treatment techniques] Zhonghua Kou Qiang Yi Xue Za Zhi. 2018;53(8):539-45.

18. Chi CW, LiCC, Lin CP, Shin CS. Cyclic fatigue behavior of nickel-titanium dental rotary files in clinical simulated root canals. J Formos Med Assoc. 2017;116(4):306-12

19. Gambarini G, Piasecki L, Miccoli G, Gaimari G, Di Giorgio R, Di Nardo D, et al. Classification and cyclic fatigue evaluation of new kinematics for endodontic instruments. Aust Endod J. 2019;45(2):154-62.

20. Modesto TC, Acosta ECP, Resende PD, PereiraÉSJ, Peixoto I, Buono VTL, et al. Cyclic flexural fatigue resistance of NiTi Controlled Memory and Blue Technology instruments after torsional preloading. J Appl Oral Sci. 2018;26:e20180144.

21. Tanomaru-Filho M, Galletti Espir C,Carolina Venção A, Macedo-Serrano N, Camilo-Pinto J, Guerreiro-Tanomaru J. Cyclic fatigue resistance of heattreated nickel-titanium instruments. Iran Endod J. 2018;13(3):312-7.

22. Ferreira F,Adeodato C, Barbosa I, Aboud L, Scelza P,Zaccaro Scelza M. Movement kinematics and cyclic fatigue of NiTi rotary instruments: a systematic review. Int Endod J. 2017;50(2):143-52.

23. Keleş A, Eymirli A, Uyanık 0, Nagas E. Influence of static and dynamic cyclic fatigue tests on the lifespan of four reciprocating systems at different temperatures. Int Endod J. 2019;52(6):880-6.
24. Pedullà E Lo Savio F, Boninelli S, Plotino G, Grande NM, Rapisarda E, etal. Influence of cyclic torsional preloading on cyclic fatigue resistance of nickel titanium instruments. Int Endod J. 2015;48(11):1043-50.

25. Alqedairi A, Alfawaz H, Abualjadayel B, Alanazi M, Alkhalifah A, Jamleh A Torsional resistance of three ProTaper rotary systems. BMC Oral Health. 2019;19(1):124.

26. Seracchiani M, Miccoli G, Reda R, Zanza A, Obino FV, Bhandi S, et al. A Comprehensive in vitro comparison of mechanical properties of two rotary endodontic instruments. World J Dent. 2020;11(3):185-8.

27. Plotino G, Testarelli L, Al-Sudani D, Pongione G, Grande NM, Gambarini G. Fatigue resistance of rotary instruments manufactured using different nickel-titanium alloys: a comparative study. Odontology. 2014;102(1):31-5.

28. Di Nardo D, Seracchiani M, Mazzoni A, Del Giudice A, Gambarini G, Testarelli L. Torque range, a new parameter to evaluate new and used instrument safety. Appl Sci. 2020;10(10):3418.

29. Gambarini G, Miccoli G, D'Angelo M, Seracchiani M, Obino FV, Reda Retal. The relevance of operative torque and torsional resistance of nickel-titanium rotary instruments: A preliminary clinical investigation. Saudi Endod J. 2020;10(3):260-4

\section{Rodolfo Reda}

\section{(Corresponding address)}

Sapienza University of Rome, Department of Oral and Maxillo Facial Sciences, Rome, Italy. 